\title{
Plasmodium species occurrence, temporal distribution and interaction in a child-aged population in rural Burkina Faso
}

Awa Gnémé ${ }^{*}$, Wamdaogo M Guelbéogo ${ }^{2}$, Michelle M Riehle, Alfred B Tiono ${ }^{2}$, Amidou Diarra², Gustave B Kabré1, N'falé Sagnon ${ }^{2}$ and Kenneth D Vernick ${ }^{3,4}$

\begin{abstract}
Background: Malaria can be caused by five Plasmodium species. Due to their higher prevalence, much of the research concentrates on Plasmodium falciparum and Plasmodium vivax. In Burkina Faso, where P. falciparum co-exists with Plasmodium malariae and Plasmodium ovale, there is not much data about the prevalence of the latter two species across human population. Moreover, interactions between co-infecting Plasmodium species are not documented. The aim of the current research is to determine species-specific prevalence and temporal distribution. The potential interactions between co-infecting Plasmodium species amongst the child-aged population in Burkina Faso are also discussed.

Methods: The study took place in the Sudanese savannah zone in Burkina Faso in a rural village, Laye. Surveys were conducted during the wet season across four years, 2007 to 2010. Volunteers aged three to 15 years with parental signed consent were enrolled. Ten children per week were screened for any history of pain, fever. Parasitological data were obtained by blood slide processing.
\end{abstract}

Results: Three sympatric Plasmodium species were recorded during this study with an average prevalence of $70.7 \%$. Species temporal distribution showed an increase of $P$. malariae parasite prevalence from $0.9 \%$ in 2007 to $13.2 \%$ in 2010. Within a season, $P$. falciparum occurred in the overall study period while $P$. malariae and $P$. ovale were highly prevalent after the rainy part of this period. Species-specific infection analysis showed that in a comparison of mono-infections, $P$. malariae gametocyte prevalence and median density were higher than those of $P$. falciparum (88.9\% vs $34.5 \%$ and 124.0 vs 40.0 gametocytes/ $\mu$, respectively). Likewise, in $P$. falciparum co-infections with P. malariae or $P$. ovale, gametocyte prevalence was also higher than in $P$. falciparum mono-infection. However, in $P$. falciparum mixed infection with P. malariae, P. falciparum gametocyte prevalence and median density as well as asexual form density decreased compared to $P$. falciparum mono-infection while for $P$. malariae mono-infection, only asexual form density significantly vary.

Conclusion: These data revealed high gametocyte prevalence in other Plasmodium species than $P$. falciparum with a significant variation of $P$. malariae gametocyte carriers and gametocyte density across years. Molecular tools and entomological studies are needed to highly assess species-specific contribution to malaria transmission.

Keywords: Malaria, Plasmodium, Species, Infection, Gametocytes, Laye, Burkina faso

\footnotetext{
* Correspondence: gplouise@yahoo.fr

'Université de Ouagadougou, Ouagadougou, Burkina Faso

Full list of author information is available at the end of the article
} 


\section{Background}

Malaria remains a huge burden for human populations living in tropical areas. More than two million malaria cases were recorded in 2010, with the heaviest mortality rates in children living in sub-Saharan Africa [1]. During the past decade, the scale-up of malaria control interventions has resulted in considerable reductions in morbidity and mortality associated with malaria in parts of Africa [2,3]. Despite these efforts, malaria continues to pose a major public health threat in many African countries [1] and recent work suggests that control efforts can be followed by infections rebounding to preintervention levels [4]. Successful local strategies for malaria control could be based on malaria surveys, which are an important tool to investigate the impact of the disease on population health status in endemic areas [5]. A primary component for this kind of survey should be the determination of parasite species diversity because optimal control measures are different for the different species of malaria.

Currently, malaria can be caused by five Plasmodium species which include Plasmodium falciparum, Plasmodium malariae, Plasmodium ovale, Plasmodium vivax and, more recently, Plasmodium knowlesi [6]. Plasmodium falciparum is the most prevalent in Africa and the most pathogenic of these, but in most malaria endemic regions multiple sympatric species are found and coinfection within individual human hosts or the mosquito vector population is common. In Africa, P. malariae is the species most frequently found in sympatry with P. falciparum [7]. Plasmodium inter-species interactions have been the focus of interest of number of studies [8-11]. The co-infecting species interactions in humans can modify within-host dynamics $[12,13]$ and alter transmission potential [8]. The effect of mixed species infections on clinical outcome has been described as both beneficial [14] and adverse [15]. Indeed, in areas where $P$. falciparum co-occurred with $P$. malariae, field studies reveal that this co-occurrence can reduce disease severity [16,17], give a lower peak of parasitaemia [18] or boost $P$. falciparum gametocyte production $[8,9]$.

In Burkina Faso particularly, where P. falciparum coexists with $P$. malariae and $P$. ovale, there is not much data about the interaction of co-infecting species. In fact, only a few studies even report the prevalence of the last two species across human population [5,19-21]. Most of these studies were done in the past decade before the scale up of interventions such as the availability of artemisinin combination therapy (ACT) or the mass distribution of insecticide-treated bed nets (ITNs). In addition, the country profile reveals an increase in malaria cases from 2008 to 2010 without any information on $P$. malariae and $P$. ovale [1], while some research highlighted a substantial $P$. ovale malaria burden in
sub-Saharan Africa [22,23]. Moreover, in Burkina Faso, where the carriage of $P$. falciparum gametocyte is important with a substantial submicroscopic part [24], the role of $P$. malariae or $P$. ovale to this gametocytaemia should be assessed. The aim of the current study was to determine Plasmodium species-specific parasite and gametocyte prevalence, their temporal distribution and potential interaction across a child-aged population from a rural village in Burkina Faso.

\section{Methods \\ Study area and period}

The study took place in Laye, a small rural village located $30 \mathrm{~km}$ north of Ouagadougou, Burkina Faso $\left(12^{\circ} 31^{\prime} \mathrm{N}, 1^{\circ} 46^{\prime} \mathrm{W}\right)$. This village is situated in a Sudanese savannah zone with one rainy season from June to October with some fluctuation across years. In the village, health care facilities are available and it is also a part of the demographic surveillance system (DSS) used by the malaria research centre of Burkina Faso for epidemiological studies. Residents live by subsistence farming in this Sudanese savannah area with seasonal holoendemic malaria. Malaria prevalence is highest in the rainy season from June to October and peaks around September. Plasmodium falciparum is responsible for the major proportion of malaria infections [20]. Malaria vectors are Anopheles gambiae complex members and Anopheles funestus groups with other minor vectors [25]. The present survey was conducted in the wet season for four consecutive years from 2007 to 2010. The study was coupled with mosquito larvae sampling with data collection beginning when breeding sites were productive. Thus, the exact time of samples collection was determined by the beginning of the rains and varied across the four sampling years.

\section{Study population}

The study population included children aged three to 15 years. Based on the most recent update of the DSS database, a list of potential children to be enrolled was done each year. Once a week, the households of a computer-generated sample of 10 children were visited by a field worker and a member of the research staff to obtain informed consent for the participation of these children in the study. Only volunteer children with signed consent were brought to the CNRFP (Centre National de Recherche et de Formation sur le Paludisme), the national malaria research centre, and enrolled for parasite detection. In situ, they were asked for any history of pain and examined by a physician. Axillary temperature was taken and a blood sample by finger prick was collected. 


\section{Blood slides collection and parasites counting}

The blood slide processing was made from finger-prick blood of each individual. The slides were left to air dry and stained with 5\% Giemsa for $35 \mathrm{~min}$. One hundred high-power fields (HPF) were examined, and the number of malaria parasites of each species and stage was recorded. The number of parasites per $\mathrm{ml}$ of blood was calculated, assuming 200 white blood cells per highpower field and a fixed white cell count of $8,000 / \mu \mathrm{l}$. Each blood slide sample was read independently by two microscopists. The mean of the results of both microscopists was taken as the parasite density. In the event of a discrepancy between the two readers, in terms of species, presence or absence of malaria parasites, or if parasite densities differed by more than $30 \%$, a third reader was involved. In this case, the arithmetic mean of the two closest readings was used as the final value for parasite density. A slide was considered negative if no parasite stage were seen after the examination of 100 fields.

\section{Ethical consideration}

The study protocol was reviewed and approved by the ethics committee for biomedical research of the Ministry of Health of Burkina Faso (code $\mathrm{N}^{\circ}$ 2006-032). The study procedures, benefits and risks were explained to the children's parents or legal guardians and their signed consent was obtained. After each assay, symptomatic subjects were treated with the combination of artemetherlumefantrine $\left(\right.$ Coartem $\left.^{\circledR}\right)$ according to relevant regulations of Burkina Faso's Health Ministry. Asymptomatic subjects were followed up by the field worker in the week.

\section{Meteorological data}

The daily rainfall data come from the DGMAC, (Direction Générale de la Météorologie et de l'Aviation Civile), the country meteorological data collection and reporting system. The monthly mean rainfall was use for analysis.

\section{Data analysis}

Comparison of prevalence was done using the Pearson's Chi square test or Fisher's exact test with contingency tables. For parasite density, the non-parametric Wilcoxon rank test for two samples or Kruskal-Wallis test for more than two samples was used. Spearman test of correlation was used to assess the link between rainfall and Plasmodium density. The potential interaction was assessed by comparing species-specific mono-infection to mixed infection. Statistical analyses were performed in $\mathrm{R}$ 2.10.1 using the R Commander Package [26]. P-value of 0.05 or lower was considered statistically significant.

\section{Results}

Study population characterization

Some 830 children $(212,274,177$ and 167 from transmission seasons 2007, 2008, 2009 and 2010, respectively) participated in the study. The mean age in the study group was $8.1 \pm 1.7$ years. Children of both genders took equal part in this study: $52.9 \%$ (males) vs $47.1 \%$ (females). Across years, gender distribution (Table 1) did not vary significantly $\left(x^{2}=0.15, \mathrm{df}=3, \mathrm{p}\right.$-value $\left.=0.98\right)$. On average, across years, $18.8 \%$ of the study population presented with fever and $76.3 \%$ of these fever cases were coupled with Plasmodium infection.

Plasmodium species occurrence and temporal distribution In the study period, three parasite species: P. falciparum, $P$. malariae and P. ovale were identified. Across years, the average Plasmodium infection prevalence was $70.7 \%$. Plasmodium falciparum was the predominant species with a prevalence of $68.19 \%$ followed by $P$. malariae (6.51\%) and $P$. ovale (1.08\%). Several mixed infections were reported with co-infection of $P$. falciparum and P. malariae $(4.34 \%)$ and co-infection of $P$. falciparum with $P$. ovale $(0.72 \%)$. No co-infections of $P$. malariae with $P$. ovale were observed, though with their low overall infection prevalence this is not surprising.

In addition, from 2007 to 2010, Plasmodium infection prevalence showed slight variation with gametocyte prevalence being significantly different across the four seasons $\left(x^{2}=12.8, \mathrm{df}=3, \mathrm{p}\right.$-value $\left.=0.005\right)$. Plasmodium malariae infection prevalence was also variable across years (Fisher's Exact Test, p-value $=3.93 \mathrm{e}-06$ ) with an increase from $0.9 \%$ in 2007 to $13.2 \%$ in 2010 (Table 2). As with $P$. malariae overall parasite infection prevalence, gametocyte prevalence also showed a variation across years with higher gametocyte prevalence (14.1\%) in 2010. However, P. falciparum and P. ovale infection prevalence do not significantly vary between the transmission seasons.

Table 1 Study population characteristics

\begin{tabular}{lllll}
\hline \multicolumn{5}{c}{ Percentage of children per seasons } \\
\cline { 2 - 5 } & $\begin{array}{l}\mathbf{2} \mathbf{2 0 0 7} \\
(\mathbf{n}=\mathbf{2 1 2})\end{array}$ & $\begin{array}{l}\mathbf{2 0 0 8} \\
\mathbf{( n = 2 7 4 )}\end{array}$ & $\begin{array}{l}\mathbf{2 0 0 9} \\
\mathbf{( n = 1 7 7 )}\end{array}$ & $\begin{array}{l}\mathbf{2 0 1 0} \\
\mathbf{( n = 1 6 7 )}\end{array}$ \\
\hline Age in years & & & \\
mean (SD*) & $9.5(3.4)$ & $7.6(1.8)$ & $7.7(1.3)$ & $7.6(1.1)$ \\
Median (IQR*) & $9.6(7.1-12.0)$ & $7.4(6.0-9.3)$ & $7.4(6.6-8.7)$ & $7.7(6.7-8.4)$ \\
Genders,\% & & & & \\
Female & 46.7 & 47.4 & 48.0 & 46.1 \\
Male & 53.3 & 52.6 & 52.0 & 53.9 \\
Fever & 21.2 & 20.1 & 22.0 & 10.2 \\
\hline
\end{tabular}

*SD = Standard deviation, $\mathrm{IQR}=$ Interquartile Range. 
Table 2 Plasmodium species prevalence across years in the overall population

\begin{tabular}{|c|c|c|c|c|c|c|}
\hline & \multicolumn{4}{|c|}{ Seasons } & \multirow[b]{2}{*}{$p$-value } \\
\hline & & 2007 & 2008 & 2009 & 2010 & \\
\hline \multirow{5}{*}{$\begin{array}{c}\text { Parasite } \\
\text { Prevalence (\%) }\end{array}$} & $\begin{array}{l}\text { Number of } \\
\text { children }\end{array}$ & 212 & 274 & 177 & 167 & \\
\hline & All Plasmodium & 64.2 & 71.9 & 71.2 & 76.6 & 0.06 \\
\hline & P. falciparum & 63.2 & 70.4 & 66.7 & 72.5 & 0.2 \\
\hline & P. malariae & 0.9 & 5.1 & 8.5 & 13.2 & $3.93 e-06$ \\
\hline & P. ovale & 0.5 & 0.7 & 1.7 & 1.8 & 0.5 \\
\hline \multirow{5}{*}{$\begin{array}{c}\text { Gametocyte } \\
\text { Prevalence (\%) }\end{array}$} & $\begin{array}{l}\text { Number of } \\
\text { infected } \\
\text { children }\end{array}$ & 136 & 197 & 126 & 128 & \\
\hline & All Plasmodium & 33.8 & 36.0 & 38.1 & 53.1 & 0.005 \\
\hline & P. falciparum & 30.9 & 31.5 & 26.2 & 40.6 & 0.09 \\
\hline & P. malariae & 2.2 & 3.6 & 11.1 & 14.1 & $9.5 e-05$ \\
\hline & P. ovale & 0.7 & 1.0 & 1.6 & 1.6 & 0.8 \\
\hline
\end{tabular}

${ }^{*} p$-value tests for variation across years.
Within season, species distribution was different with $P$. falciparum being present throughout the study period while $P$. malariae and $P$. ovale often occurred following the rainy part of the study period (Figure 1A). In addition, $P$. falciparum reached its maximum density during the rainy part of the study period, while $P$. malariae and $P$. ovale often peaked nearer the end of this rainy period (Figure 1B). Moreover, Spearman test of correlation, reported a significant positive link between P. falciparum density and rainfall (rho $=0.727$, $\mathrm{p}$-value $=0.0004)$. However, $P$. malariae and $P$. ovale density were not significantly correlated with rainfall (respectively rho $=-0.153, \mathrm{p}$-value $=0.53$ and $\mathrm{rho}=$ 0.013 , $\mathrm{p}$-value $=0.96$ ).

\section{Species characteristics among the infected population}

Species-specific mono-infection and mixed infection characteristics are given in Table 3. The median age as well as gametocyte prevalence and median density show significant variation across species infected children (see Table 3). Comparisons of mono-infections characteristics show significant difference for gametocytes prevalence and density (Fisher's Exact Test, p-value $=1.5 \mathrm{e}-06$ and Kruscal-Wallis test, $\mathrm{HW}=15.62, \mathrm{df}=2$, $\mathrm{p}$-value $=0.0004$

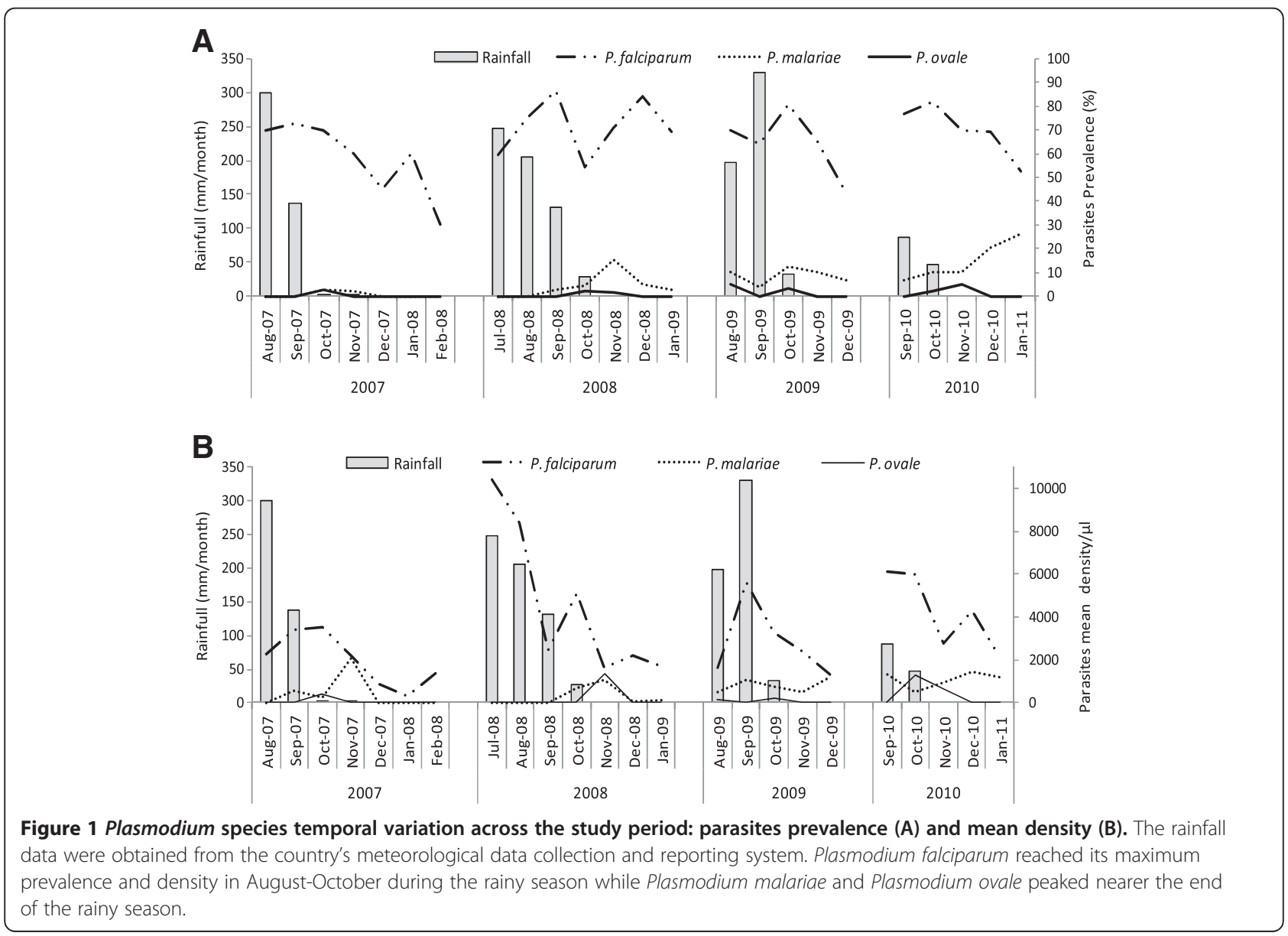


Table 3 Baseline characteristics of Plasmodium species infected children*

\begin{tabular}{lllllll}
\hline & $\begin{array}{l}\text { Age, years, } \\
\text { median (IQR) }\end{array}$ & Sex, \% male (n/N) & Fever, \% (n/N) & $\begin{array}{l}\text { Gametocytes } \\
\text { carriers, \% (n/N) }\end{array}$ & $\begin{array}{l}\text { Gametocytes density, } \\
\text { median (IQR) }\end{array}$ & $\begin{array}{l}\text { Asexual forms density, } \\
\text { median (IQR) }\end{array}$ \\
\hline PF & 8.0 & 54.6 & 21.2 & 34.5 & 40.0 & 1007.5 \\
& $(6.5-9.4)$ & $(286 / 524)$ & $(111 / 524)$ & $(181 / 524)$ & $(19-78)$ & $(327-3826)$ \\
PM & 7.6 & 50.0 & 5.6 & 88.9 & 124.0 & 874.0 \\
& $(7.2-8.2)$ & $(9 / 18)$ & $(1 / 18)$ & $(16 / 18)$ & $(63-390)$ & $(603-1148)$ \\
PO & 10.0 & 0.0 & 33.3 & 66.7 & 124.5 & 277.0 \\
& $(9.6-12.2)$ & $(0 / 3)$ & $(1 / 3)$ & $(2 / 3)$ & $(122-127)$ & $(219-756)$ \\
PF + PM & 7.2 & 52.8 & 13.9 & 80.6 & 90.0 & 1337.5 \\
& $(6.3-8.2)$ & $(19 / 36)$ & $(5 / 36)$ & $(29 / 36)$ & $(38-170)$ & $(718-2031)$ \\
PF + PO & 8.0 & 50.0 & 16.7 & 83.3 & 20.0 & 6257.5 \\
& $(7.4-8.8)$ & $(3 / 6)$ & $(1 / 6)$ & $(5 / 6)$ & $(19-95)$ & $(2692-7476)$ \\
p-value & 0.04 & 0.5 & 0.3 & $1.7 e-12$ & 0.0001 & 0.09 \\
\hline
\end{tabular}

${ }^{*} \mathrm{PF}=P$. falciparum mono-infection; $\mathrm{PM}=P$. malariae mono-infection; $\mathrm{PF}+\mathrm{PM}=P$. falciparum and $P$. malariae co-infection; $\mathrm{PO}=P$. ovale mono-infection; $\mathrm{PF}+\mathrm{PO}=P$. falciparum and $P$. ovale co-infection; $\mathrm{IQR}=$ interquartile range.

respectively). Within these mono-infections, the gametocyte prevalence was higher in $P$. malariae infections than in $P$. falciparum infections $(88.9 \%$ vs. $34.5 \%$ respectively, $\quad x^{2}=22.2, \quad \mathrm{df}=1, \quad \mathrm{p}$-value $\left.=2.4 \mathrm{e}-06\right) . \quad$ The median gametocyte density shows the same trend with higher values being observed in $P$. malariae infections than in $P$. falciparum infections (124.0 vs. 40.0 gametocytes $/ \mu \mathrm{l}$, Wilcoxon rank test, $\mathrm{W}=668$, p-value $=$ 0.0003). No significant difference was found between $P$. ovale gametocytes carriage or median gametocyte density and either of the other Plasmodium species.

For age variation, the median age was significantly higher for $P$. ovale mono-infections (10.0 years, IQR, 9.6-12.2) than for P. malariae (7.6 years; Wilcoxon rank test, $\mathrm{W}=3, \mathrm{p}$-value $=0.02$ ) or $P$. falciparum (8.0 years; $\mathrm{W}=214$, $\mathrm{p}$-value $=0.03$ ). Variables such as gender, prevalence of fever, and asexual form median density, did not show significant difference across monoinfections.

Interestingly, significant differences were observed between parasite species mono-infections and their mixed infections for variables such as gametocytes prevalence or density, asexual forms density, and infected children median age. By comparing P. falciparum monoinfections to its mixed infections, the study report that gametocyte prevalence and median gametocyte density were lower in mono-infections than co-infections with P. malariae (34.5 vs 80.6; $\mathrm{X}^{2}=30.4, \mathrm{p}=3.5 \mathrm{e}-08$ and 40.0 vs 90.0; $\mathrm{W}=1,690$, $\mathrm{p}$-value $=0.002$ respectively). However, the median age of infected-children was higher in $P$. falciparum mono-infections than in co-infections with P. malariae (7.2 vs 8.0; $\mathrm{W}=11,430.5$, $\mathrm{p}$-value $=0.03)$.

When looking at $P$. falciparum mixed infection with $P$. ovale, gametocyte prevalence and asexual form density were higher in mixed infections than in $P$. falciparum mono-infections (83.3 vs 34.5; Fisher exact test, p-value =
0.02 and 6,257.5 vs 1,007.5; $\mathrm{W}=691$, p-value $=0.02$ ). Other variables did not shown significant variation.

For $P$. malariae and $P$. ovale mono-infections and their mixed infections with $P$. falciparum, no significant difference was found between $P$. malariae mono $(\mathrm{n}=18)$ and mixed infections $(\mathrm{n}=36)$, while $P$. ovale had a higher median density of asexual forms in mixed infections compared to mono-infections $(6,257.5$ vs 277.0; $\mathrm{W}=18, \mathrm{p}$-value $=0.02$ ). Table 4 summarizes the species-specific infection pair comparisons.

\section{Species characteristic among Plasmodium specific- infected children}

To assess species interaction, species-specific characteristics in mono- and mixed infections were compared. Plasmodium falciparum gametocyte prevalence, gametocyte median density as well as the median asexual form density in mono-infections was higher than those in mixed infections with $P$. malariae $\left(\mathrm{X}^{2}=4.8, \mathrm{df}=1\right.$, $\mathrm{p}$-value $=0.03, \quad \mathrm{~W}=879.5, \quad \mathrm{p}$-value $=0.009$ and $\mathrm{W}=$ $10,849.5$, p-value $=0.03$ respectively) (see Table 5 ). In its co-infection with $P$. ovale, no significant difference was observed for either gametocyte prevalence $33.3 \%$ vs $34.5 \%$ ) or gametocyte density (23.5 vs 40.0 gametocytes/ $\mu \mathrm{l}$ ) in comparison with mono-infection (Fisher exact test, $\mathrm{p}=1.0$ and Wilcoxon rank test, $\mathrm{p}=0.2$ respectively). However, $P$. falciparum asexual form median density was higher in its co-infection with $P$. ovale $(5,563.5$ parasites/ $\mu \mathrm{l})$ compared to mono-infection $(1,007.5$ parasites $/ \mu \mathrm{l})(\mathrm{W}=758, \mathrm{p}$-value $=0.04)$.

Among $P$. malariae-infected children, only asexual forms median density shows a significant difference (W $=163$, p-value $=0.003$ ) between mono-infections and mixed infections (Table 5). Plasmodium ovale does not show any significant variation between mono- and mixed infections. 
Table 4 Plasmodium species-specific infection comparison significant level *

\begin{tabular}{lllllll}
\hline & $\begin{array}{l}\text { Age, years, } \\
\text { Median (IQR) }\end{array}$ & $\begin{array}{l}\text { Sex, \% male } \\
(\mathbf{n} / \mathbf{N})\end{array}$ & $\begin{array}{l}\text { Fever, } \\
(\mathbf{n} / \mathbf{N})\end{array}$ & $\begin{array}{l}\text { Gametocytes } \\
\text { carriers, \% (n/N) }\end{array}$ & $\begin{array}{l}\text { Gametocytes density, } \\
\text { Median (IQR) }\end{array}$ & $\begin{array}{l}\text { Asexual forms } \\
\text { density, Median (IQR) }\end{array}$ \\
\hline PF vs PM vs PO & 0.08 & 0.2 & 0.2 & $1.5 e-06$ & 0.0004 & 0.4 \\
PF vs PM & 0.8 & 0.7 & 0.1 & $2.436 \mathrm{e}-06$ & 0.0003 & 0.5 \\
PF vs PO & 0.04 & 0.09 & 0.5 & 0.3 & 0.07 & 0.2 \\
PM vs PO & 0.02 & 0.2 & 0.3 & 0.4 & 1.0 & 0.2 \\
PF vs PF + PM & 0.03 & 0.8 & 0.3 & $3.5 \mathrm{e}-08$ & 0.002 & 0.5 \\
PF vs PF + PO & 0.7 & 0.8 & 1.0 & 0.02 & 0.7 & 0.02 \\
PM vs PF + PM & 0.1 & 0.8 & 0.6 & 0.7 & 0.3 & 0.1 \\
PO vs PF + PO & 0.05 & 0.1 & 1.0 & 1.0 & 0.4 & 0.002 \\
\hline
\end{tabular}

${ }^{*} \mathrm{PF}=P$. falciparum mono-infection; $\mathrm{PM}=P$. malariae mono-infection; $\mathrm{PF}+\mathrm{PM}=P$. falciparum and $P$. malariae co-infection; $\mathrm{PO}=P$. ovale mono-infection; $\mathrm{PF}+\mathrm{PO}=P$. falciparum and $P$. ovale co-infection; $\mathrm{IQR}=$ interquartile range.

\section{Discussion}

Three sympatric species, $P$. falciparum, $P$. malariae and $P$. ovale were observed in the study site, with $P$. falciparum being the most prevalent species. Plasmodium falciparum infection is widely prevalent across the entire study period with some monthly fluctuation while $P$. malariae and $P$. ovale individually peak at the end of the rainy part of the study period. Similar fluctuation between $P$. malariae and $P$. falciparum densities has been reported by several other studies $[19,27]$. Offset peaks may be explained by competition between both species and the fact that immune-protection induced by infection with $P$. falciparum does not seem to be effective against $P$. malariae [19]. It has also been suggested that $P$. malariae can be found at higher prevalence when transmission and overall infection rates are lower and it is alleviated from the suppressive effect of $P$. falciparum $[10,18]$. A similar phenomenon may explain $P$. ovale occurrence. This finding revealed a kind of alternation in the relative contribution of each species to the total parasite indexes that occurred in the study area [28].

The significant increase of $P$. malariae prevalence throughout the four-year study period allows speculation on positive selection of this parasite by medication. In fact, in the study site and its surrounding villages many research activities occurred with treatment of symptomatic children $[24,29,30]$ or a trial for intermittent preventive treatment of malaria in children (IPTc) [31,32]. These symptomatic cases are rarely $P$. malariae infected-children because of this species low density. As a result, $P$. malariae remains in circulation despite the treatment and its transmission goes up in the

Table 5 Species-specific characteristics among mono-infection or mixed infection*

\begin{tabular}{|c|c|c|c|}
\hline & $\begin{array}{l}\text { Gametocytes } \\
\text { carriers }\end{array}$ & $\begin{array}{l}\text { Gametocytes } \\
\text { density }\end{array}$ & $\begin{array}{l}\text { Asexual parasites } \\
\text { density }\end{array}$ \\
\hline & $\%(n / N)$ & Median (IQR) & Median (IQR) \\
\hline \multicolumn{4}{|c|}{ Plasmodium falciparum infection characteristics } \\
\hline PF & $34.5(181 / 524)$ & $40.0(19-78)$ & $1007.5(327-3826)$ \\
\hline $\mathrm{PF}+\mathrm{PM}$ & $16.7(6 / 36)$ & $16.0(10-22)$ & $645.0(200-1277)$ \\
\hline $\mathrm{PF}+\mathrm{PO}$ & $33.3(2 / 6)$ & $23.5(16-31)$ & $5563.5(2510-7163)$ \\
\hline$P F$ vs $P F+P M, p$-value & 0.03 & 0.01 & 0.03 \\
\hline$P F$ vs $P F+P O, p$-value & 1.0 & 0.2 & 0.04 \\
\hline \multicolumn{4}{|c|}{ Plasmodium malariae infection characteristics } \\
\hline PM & $88.9(16 / 18)$ & $124.0(63-390)$ & $874.0(603-1148)$ \\
\hline $\mathrm{PF}+\mathrm{PM}$ & $72.2(26 / 36)$ & $99.0(49-173)$ & $377.5(132-751)$ \\
\hline$P M$ vs $P F+P M, p$-value & 0.3 & 0.5 & 0.003 \\
\hline \multicolumn{4}{|c|}{ Plasmodium ovale infection characteristics } \\
\hline PO & $66.7(2 / 3)$ & $124.5(122-127)$ & $277.0(219-756)$ \\
\hline $\mathrm{PF}+\mathrm{PO}$ & $83.3(5 / 6)$ & $20.0(19-56)$ & $341.0(183-733)$ \\
\hline$P O$ vs $P F+P O, p$-value & 1.0 & 0.4 & 0.9 \\
\hline
\end{tabular}

${ }^{*} \mathrm{PF}=P$. falciparum mono-infection; $\mathrm{PM}=P$. malariae mono-infection; $\mathrm{PF}+\mathrm{PM}=P$. falciparum and $P$. malariae co-infection; $\mathrm{PO}=P$. ovale mono-infection; $\mathrm{PF}+\mathrm{PO}=P$. falciparum and $P$. ovale co-infection; $\mathrm{IQR}=$ interquartile range. 
population. More, with the absence of $P$. falciparum due to drug, $P$. malariae prevalence and density goes up because of the suppressive effect of $P$. falciparum $[10,18]$. In all cases, particular attention should be paid to this secondary parasite. These secondary parasite species should not be ignored particularly as control interventions are planned and evaluated. Entomological studies are also needed to identify anopheline species which breed around the site and assess their vectorial capacity for a better understanding of this increased $P$. malariae prevalence.

In addition, the high proportion of gametocyte carriers and gametocyte density observed among $P$. malariaeinfected children during the study period, suggests that specific attention should be paid to this parasite. Indeed, gametocytes are the currency of transmission from human to mosquito for maintaining the malaria transmission cycle. The presence and infectiousness of gametocytes in circulation determines the success of transmission from humans to mosquitoes. For now, $P$. malariae gametocyte density and mosquito infection are not well documented. Nevertheless it is well known that lower Plasmodium density as well as submicroscopic density is infectious to mosquitoes [24,33]. Although considered mild, P. malariae is known to cause chronic infections which can last for years and might reoccur decades after initial exposure when people have long since left endemic regions [34]. Any level of infection with this species should be taken into account with relevant treatment. Moreover, this study reports a decrease of $P$. malariae asexual forms density and gametocytes prevalence when $P$. falciparum is present. With vaccine leading to the absence of $P$. falciparum, the inhibitory effect on $P$. malariae may disappear. Then, parasitaemia and gametocyte carriage of $P$. malariae could increase and maintain severe malaria infection. Within the context of vaccine being developed against $P$. falciparum [35], this finding presents a great epidemiological issue because the presence of nonfalciparum species will still be a serious health concern to the communities at risk of infection.

The current data reveal that $P$. falciparum- and $P$. malariae-specific gametocyte prevalence, gametocyte and asexual form densities were higher in monoinfection as compared to mixed infections. In summary, the implications of these observations may have a profound repercussion in the outcome of disease control. If the simultaneous infection by other species inhibits $P$. falciparum-gametocyte production [36] and if control measures affect and reduce more effectively Plasmodium species other than P. falciparum, this inhibitory effect may disappear [28]. This finding is in agreement with some previous studies on P. falciparum [28,36]. Indeed in Thailand, Price et al. [36] reported that mixed infections with $P$. falciparum and $P$. vivax are associated with a reduction in the prevalence of $P$. falciparum gametocytes. In the same way, Marques et al. [28] found in Mozambique that P. falciparum gametocytes predominated in single infections. In contrast, it has been reported from studies conducted in Columbia and Kenya that $P$. malariae infection enhanced production of $P$. falciparum gametocytes $[8,9]$. These conflicting results suggest that the relationship between mixed species infections and gametocytaemia may be different under different endemicities [9].

Then, variability in the interactions between species under different transmission intensities, coupled with different sympatric species combinations may contribute to observed differences in the epidemiology and clinical presentations of malaria between endemic regions [10,37].

Finally, prevalences and densities recorded in the current study may underestimate the real part of each Plasmodium species. Much study report that parasite prevalence under microscopy is 2.5 -fold lower compared to prevalence found with molecular method and this fold difference was consistent across the different transmission levels in individual studies [38-40] or metaanalysis [41]. In light of these results, a longitudinal parasitological survey using both microscopy and molecular tool are necessary to assess species-specific real prevalence for a better understanding of species interaction. An entomological study is also need to evaluate minor species gametocyte infectiousness and their contribution to malaria transmission.

\section{Conclusion}

Three species of malaria parasite are in circulation in the study area, with a fluctuation of $P$. falciparum and other species prevalence. These data revealed high gametocyte prevalence in other Plasmodium species than $P$. falciparum. The high proportion of gametocyte carriers and gametocyte density across $P$. malariaeinfected children as well as the increase observed across years, presents a great epidemiological issue in the context of a vaccine being developed against $P$. falciparum. The relevance of these data should be taken into account when general control strategies are planned.

\section{Competing interest}

The authors declare that they have no competing interests.

\section{Authors' contributions}

$A G, W M G, A B T, A D$ participated in data collection and laboratory procedures. AG, WMG, GBK, MMR, N'FS and KDV conceived and designed the experiments. AG, GBK, analysed the data and wrote the manuscript. All authors reviewed and revised the manuscript. N'FS and KDV coordinated and participated to fund acquisition. All authors read and approved the final manuscript. 


\section{Acknowledgements}

We are grateful to children and their parents from Laye for their participation to this study. We also thank the staff of CNRFP for his technical assistance. This work received financial support from the American National Institute of Health $(\mathrm{NIH})$. We are grateful to anonymous reviewers for their helpful comments.

\section{Author details}

${ }^{1}$ Université de Ouagadougou, Ouagadougou, Burkina Faso. ${ }^{2}$ Centre National de recherche et de Formation sur le Paludisme, Ouagadougou, Burkina Faso. ${ }^{3}$ Unité de Génétique et Génomique des Insectes Vecteurs, Département de Parasitologie et Mycologie, Institut Pasteur de Paris, Paris, France.

${ }^{4}$ Department of Microbiology, University of Minnesota, Minnesota, USA.

Received: 27 October 2012 Accepted: 18 February 2013 Published: 19 February 2013

\section{References}

1. WHO: World Malaria Report 2011. Geneva: World Health Organization/Global Malaria Programme; 2012.

2. O'Meara WP, Mangeni JN, Steketee R, Greenwood B: Changes in the burden of malaria in sub-Saharan Africa. Lancet Infect Dis 2010, 10:545-555.

3. Steketee RW, Campbell CC: Impact of national malaria control scale-up programmes in Africa: magnitude and attribution of effects. Malar J 2010, 9:299.

4. Trape JF, Tall A, Diagne N, Ndiath O, Ly AB, Faye J, Dieye-Ba F, Roucher C, Bouganali C, Badiane A, Sarr FD, Mazenot C, Toure-Balde A, Raoult D, Druilhe P, Mercereau-Puijalon O, Rogier C, Sokhna C: Malaria morbidity and pyrethroid resistance after the introduction of insecticide-treated bednets and artemisinin-based combination therapies: a longitudinal study. Lancet Infect Dis 2011, 11:925-932.

5. Stich A, Oster N, Abdel-Aziz IZ, Stieglbauer G, Coulibaly B, Wickert H, McLean J, Kouyate BA, Becher H, Lanzer M: Malaria in a holoendemic area of Burkina Faso: a cross-sectional study. Parasitol Res 2006, 98:596-599.

6. Singh B, Lee KS, Matusop A, Radhakrishnan A, Shamsul SSG, Cox-Singh J, Thomas A, Conway DJ: A large focus of naturally acquired Plasmodium knowlesi infections in human beings. Lancet 2004, 363:1017-1024.

7. Collins WE, Jeffery GM: Plasmodium malariae: parasite and disease. Clin Microbiol Rev 2007, 20:579-592.

8. McKenzie FE, Jeffery GM, Collins WE: Plasmodium malariae infection boosts Plasmodium falciparum gametocyte production. AmJTrop Med Hyg 2002, 67:411-414.

9. Bousema JT, Drakeley CJ, Mens PF, Arens T, Houben R, Omar SA, Gouagna LC, Schallig H, Sauerwein RW: Increased Plasmodium falciparum gametocyte production in mixed infections with $P$. malariae. AmJTrop Med Hyg 2008, 78:442-448.

10. Richie T: Interactions between malaria parasites infecting the same vertebrate host. Parasitology 1988, 96:607-639.

11. Snounou G, Bourne T, Jarra W, Viriyakosol S, Brown KN: Identification and quantification of rodent malaria strains and species using gene probes. Parasitology 1992, 105(Pt 1):21-27.

12. Bruce MC, Day KP: Cross-species regulation of Plasmodium parasitemia in semi-immune children from Papua New Guinea. Trends Parasitol 2003, 19:271-277.

13. Bruce MC, Donnelly CA, Alpers MP, Galinski MR, Barnwell JW, Walliker D, Day KP: Cross-species interactions between malaria parasites in humans. Science 2000, 287:845-848.

14. Smith T, Genton B, Baea K, Gibson N, Narara A, Alpers MP: Prospective risk of morbidity in relation to malaria infection in an area of high endemicity of multiple species of Plasmodium. AmJTrop Med Hyg 2001, 64:262-267.

15. May J, Falusi AG, Mockenhaupt FP, Ademowo OG, Olumese PE, Bienzle U, Meyer CG: Impact of subpatent multi-species and multi-clonal plasmodial infections on anaemia in children from Nigeria. Trans $R$ Soc Trop Med Hyg 2000, 94:399-403.

16. Luxemburger C, Ricci F, Nosten F, Raimond D, Bathet S, White NJ: The epidemiology of severe malaria in an area of low transmission in Thailand. Trans R Soc Trop Med Hyg 1997, 91:256-262.
17. Black J, Hommel M, Snounou G, Pinder M: Mixed infections with Plasmodium falciparum and P. malariae and fever in malaria. Lancet 1994, 343:1095.

18. Mason DP, McKenzie FE, Bossert WH: The blood-stage dynamics of mixed Plasmodium malariae-Plasmodium falciparum infections. J Theor Biol 1999, 198:549-566.

19. Boudin C, Robert V, Verhave JP, Carnevale P, Ambroise-Thomas P: Plasmodium falciparum and $P$. malariae epidemiology in a West African village. Bull World Health Organ 1991, 69:199-205.

20. Habluetzel A, Cuzin N, Diallo DA, Nebié I, Belem S, Cousens SN, Esposito F: Insecticide-treated curtains reduce the prevalence and intensity of malaria infection in Burkina Faso. Trop Med Int Health 1999, 4:557-564.

21. Geiger C, Agustar H, Compaore G, Coulibaly B, Sie A, Becher H, Lanzer M, Janisch T: Declining malaria parasite prevalence and trends of asymptomatic parasitaemia in a seasonal transmission setting in north-western Burkina Faso between 2000 and 2009-2012. Malar J 2013, 12:27.

22. Sutherland CJ, Tanomsing N, Nolder D, Oguike M, Jennison C, Pukrittayakamee S, Dolecek C, Hien TT, do Rosario VE, Arez AP, Pinto J, Michon P, Escalante AA, Nosten F, Burke M, Lee R, Blaze M, Otto TD, Barnwell JW, Pain A, Williams J, White NJ, Day NP, Snounou G, Lockhart PJ, Chiodini PL, Imwong M, Polley SD: Two nonrecombining sympatric forms of the human malaria parasite Plasmodium ovale occur globally. J Infect Dis 2010, 201:1544-1550.

23. Oguike MC, Betson M, Burke M, Nolder D, Stothard JR, Kleinschmidt I, Proietti C, Bousema T, Ndounga M, Tanabe K, Ntege E, Culleton R, Sutherland CJ: Plasmodium ovale curtisi and Plasmodium ovale wallikeri circulate simultaneously in African communities. Int J Parasitol 2011, 41:677-683

24. Ouedraogo AL, Bousema T, Schneider P, de Vlas SJ, Ilboudo-Sanogo E, Cuzin-Ouattara N, Nebie I, Roeffen W, Verhave JP, Luty AJ, Sauerwein R: Substantial contribution of submicroscopical Plasmodium falciparum gametocyte carriage to the infectious reservoir in an area of seasonal transmission. PLoS One 2009, 4:e8410.

25. Petrarca V, Petrangeli G, Rossi P, Sabatinelli G: [Chromosomal study of Anopheles gambiae and Anopheles arabiensis in Ouagadougou (Burkina Faso) and various neighboring villages]. Parassitologia 1986, 28:41-61.

26. Team RDC: R: A language and environment for statistical computing. Vienna, Austria: R Foundation for Statistical Computing; 2011

27. Molineaux L, Gramiccia G: THE GARKI PROJECT. Research on the Epidemiology and Control of Malaria in the Sudan Savanna of West Africa. Geneva: World Health organisation; 1980:311pp.

28. Marques P, Saúte F, Pinto V, Cardoso S, Pinto J, Alonso P, do Rosário V, Arez A: Plasmodium species mixed infections in two areas of Manhiça District, Mozambique. Int J Biol Sci 2005, 1:96-102.

29. Ouedraogo AL, de Vlas SJ, Nebie I, Ilboudo-Sanogo E, Bousema JT, Ouattara AS, Verhave JP, Cuzin-Ouattara N, Sauerwein RW: Seasonal patterns of Plasmodium falciparum gametocyte prevalence and density in a rural population of Burkina Faso. Acta Trop 2008, 105:28-34.

30. Ouedraogo AL, Schneider P, de Kruijf M, Nebie I, Verhave JP, Cuzin-Ouattara $\mathrm{N}$, Sauerwein RW: Age-dependent distribution of Plasmodium falciparum gametocytes quantified by Pfs 25 real-time QT-NASBA in a crosssectional study in Burkina Faso. AmJTrop Med Hyg 2007, 76:626-630.

31. Konate AT, Yaro JB, Ouedraogo AZ, Diarra A, Gansane A, Soulama I, Kangoye DT, Kabore $Y$, Ouedraogo E, Ouedraogo A, Tiono AB, Ouedraogo IN, Chandramohan D, Cousens S, Milligan PJ, Sirima SB, Greenwood B, Diallo $\mathrm{DA}$ : Intermittent preventive treatment of malaria provides substantial protection against malaria in children already protected by an insecticide-treated bednet in Burkina Faso: a randomised, double-blind, placebo-controlled trial. PLoS Med 2011, 8:e1000408.

32. Konate AT, Yaro JB, Ouedraogo AZ, Diarra A, Gansane A, Soulama I, Kangoye DT, Kabore $Y$, Ouedraogo E, Ouedraogo A, Tiono AB, Ouedraogo IN, Chandramohan D, Cousens S, Milligan PJ, Sirima SB, Greenwood BM, Diallo DA: Morbidity from malaria in children in the year after they had received intermittent preventive treatment of malaria: a randomised trial. PLoS One 2011, 6:e23391.

33. Schneider P, Bousema T, Omar S, Gouagna L, Sawa P, Schallig H, Sauerwein R: Submicroscopic Plasmodium falciparum gametocytaemia in Kenyan children after treatment with sulphadoxine-pyrimethamine monotherapy or in combination with artesunate. Int J Parasitol 2006, 36:403-408. 
34. Siala E, Khalfaoui M, Bouratbine A, Hamdi S, Hili K, K A: [Relapse of Plasmodium malariae malaria 20 years after living in an endemic area] (in French). Presse Med 2005, 34:371-372.

35. Agnandji ST, Lell B, Soulanoudjingar SS, Fernandes JF, Abossolo BP, Conzelmann C, Methogo BG, Doucka Y, Flamen A, Mordmuller B, Issifou S, Kremsner PG, Sacarlal J, Aide P, Lanaspa M, Aponte JJ, Nhamuave A, Quelhas D, Bassat Q, Mandjate S, Macete E, Alonso P, Abdulla S, Salim N, Juma O, Shomari M, Shubis K, Machera F, Hamad AS, Minja R, RTS,S Clinical Trials Partnership: First results of phase 3 trial of RTS,S/AS01 malaria vaccine in African children. N Engl J Med 2011, 365:1863-1875.

36. Price R, Nosten F, Simpson JA, Luxemburger C, Phaipun L, ter Kuile F, van Vugt M, Chongsuphajaisiddhi T, White NJ: Risk factors for gametocyte carriage in uncomplicated falciparum malaria. AmJTrop Med Hyg 1999, 60:1019-1023.

37. Maitland K, Williams TN, Bennett S, Newbold Cl, Peto TE, Viji J, Timothy R, Clegg JB, Weatherall DJ, Bowden DK: The interaction between Plasmodium falciparum and P. vivax in children on Espiritu Santo island, Vanuatu. Trans R Soc Trop Med Hyg 1996, 90:614-620.

38. Harris I, Sharrock W, Bain L, Gray K-A, Bobogare A, Boaz L, Lilley K, Krause D, Vallely A, Johnson M-L, Gatton M, Shanks G, Cheng Q: A large proportion of asymptomatic Plasmodium infections with low and sub-microscopic parasite densities in the low transmission setting of Temotu Province, Solomon Islands: challenges for malaria diagnostics in an elimination setting. Malar J 2010, 9:254.

39. Steenkeste N, Rogers W, Okell L, Jeanne I, Incardona S, Duval L, Chy S, Hewitt S, Chou M, Socheat D, Babin F-X, Ariey F, Rogier C: Sub-microscopic malaria cases and mixed malaria infection in a remote area of high malaria endemicity in Rattanakiri province, Cambodia: implication for malaria elimination. Malar J 2010, 9:108.

40. Manjurano A, Okell L, Lukindo T, Reyburn H, Olomi R, Roper C, Clark TG, Joseph S, Riley EM, Drakeley C: Association of sub-microscopic malaria parasite carriage with transmission intensity in north-eastern Tanzania. Malar J 2011, 10:370.

41. Okell LC, Ghani AC, Lyons E, Drakeley CJ: Submicroscopic infection in Plasmodium falciparum-endemic populations: a systematic review and meta-analysis. J Infect Dis 2009, 200:1509-1517.

doi:10.1186/1475-2875-12-67

Cite this article as: Gnémé et al:: Plasmodium species occurrence,

temporal distribution and interaction in a child-aged population in rural Burkina Faso. Malaria Journal 2013 12:67.

\section{Submit your next manuscript to BioMed Central and take full advantage of:}

- Convenient online submission

- Thorough peer review

- No space constraints or color figure charges

- Immediate publication on acceptance

- Inclusion in PubMed, CAS, Scopus and Google Scholar

- Research which is freely available for redistribution 